\title{
ANALISIS PELAKSANAAN PROGRAM DIARE DI PUSKESMAS SERING TAHUN 2019
}

\author{
Yemima Putri Hasibuan, Rapael Ginting \\ Fakultas Kesehatan Masyarakat \\ Universitas Prima Indonesia, Medan \\ E-mail: yemimaputrihsb@yahoo.co.id \\ DOI : https://doi.org/10.35451/jkg.v2i1.219
}

\section{ABSTRACT}

Infectious diseases are still a concern of the government, one of which is diarrheal disease control programs. Sering Public Health Center Medan Tembung Subdistrict showed the number of diarrhea sufferers increased each year from 476 people in 2016, to 356 people in 2017 and 820 people in 2018. This type of research is a qualitative study. There were 6 informants in this study, consisting of 1 informant from the head of the Sering Public Health Center, 1 informant in charge of the Sering Public Health Center diarrhea program, 1 informant from PMK Medan City Office, 1 posyandu cadre informant, 2 informants from mothers of children under five whose children suffer from diarrhea. The results showed that the implementation of the diarrhea program at the Puskesmas Sering not going well. Marked by data reports that have not been made in the form of graphics, facilities and infrastructure that have not been maximized, namely the absence of posters about diarrhea in Sering Public Health Center, routine diarrhea counseling in the community, not optimal management of standard diarrhea in health facilities through the Five Steps to Complete Diarrhea, community participation in supporting the implementation of the program of diarrhea is still low, and still goes on monitoring and evaluation in accordance with what has been planned. Based on the results of the study, it is expected that the Puskesmas Sering to increase diarrhea counseling, implement diarrhea management, as well as the community to maintain environmental hygiene and carry out clean and healthy living behaviors.

Keywords: Program Implementation, Diarrhea, Sering Public Health Center 


\section{PENDAHULUAN}

Upaya pemerintah dalam menurunkan kasus diare yaitu dengan melaksanakan tatalaksana diare yang sesuai standar, surveilans epidemiologi, penanggulangan kejadial luar biasa (KLB), mengembangkan pedoman pengendalian diare, meningkatkan pengetahuan dan keterampilan petugas dalam pengelolaan program, mengembangkan jejaring lintas sektoral, pembinaan teknis dan monitoring pelaksanaan pengendalian penyakit diare (Kemenkes RI, 2011).

Salah satu upaya kesehatan yang dilakukan pemerintah dalam meningkatkan derajat kesehatan yang optimal adalah program pencegahan dan pengendalian penyakit menular. Salah satu program pemerintah terkait diare yaitu di antaranya adalah program pengendalian penyakit diare yang bertujuan untuk menurunkan angka kesakitan dan kematian karena diare bersama lintas program dan sektor terkait (Kemenkes RI, 2011).

Berdasarkan penelitian Astika (2014) menyatakan bahwa pelaksanaan program diare di puskesmas medan deli belum berjalan dengan optimal. Hal ini dikarenakan kurang tersedianya sarana kesehatan, penyuluhan tentang diare yang masih kurang, penatalaksanaan diare yang belum sesuai standar serta kurangannya pengawasan dan pembinaan dari dinas kesehatan.

Penelitian tentang tatalaksana diare oleh Hoque et al (2012) di Bangladesh, didapatkan hasil bahwa kualitas perawatan pada tatalaksana diare di rumah sakit pada 18 kabupaten belum semuanya melakukan pemantauan rehidrasi berencana sesuai dengan tingkat dehidrasi, belum menerapkan pemberian antibiotik secara selektif dan belum memberikan anjuran kepada orang tua untuk melanjutkan makan selama diare. Dari hasil penelitian oleh Zhang et al (2011) di China, didapatkan hasil bahwa dari semua anak diare yang dirawat jalan, belum mendapatkan oralit dan juga zink, serta penggunaan antibiotik masih cukup tinggi pada anak yang menderita diare.

Berdasarkan hasil dari Rencana Usulan Kegiatan (RUK) tentang program diare tahun 2017 di Puskesmas Rampal Celaket Kota Malang bahwa program diare juga belum tercapai sesuai dengan yang diharapkan. Beberapa faktor yang mempengaruhi tidak tercapainya program diare adalah kurangnya media penyuluhan (lembarbalik), kurang pelatihan kader, kurangnya jadwal penyuluhan diare pada masyarakat, tingkat pengetahuan masyarakat tentang diare yang masih kurang, serta tingkat ekonomi rendah.

\section{Puskesmas Sering merupakan} salah satu puskemas di Sumatera Utara yang berada di Kecamatan Medan Tembung. Dari data yang didapatkan oleh peneliti, penyakit diare masuk dalam jumlah kunjungan 10 penyakit terbesar yang berada di Puskesmas Sering. Berdasarkan data dari buku laporan tahunanan UPTD Puskesmas Sering jumlah penderita diare ada 467 orang (2016), 356 orang (2017), 820 orang (2018) dari data diatas terdapat peningkatan dari tahun sebelumnnya. Dari hasil pencapaian program diare yang diperoleh selama 3 tahun terakhir juga belum sesuai dengan standar yang ada. Jumlah penderita diare pada balita di puskesmas sering juga cukup memperihatinkan, tahun 2016 ada sebanyak 145 balita, tahun 2017 ada sebanyak 114 balita dan pada tahun 2018 ada sebanyak 220 balita.

Berdasarkan wawancara peneliti dengan petugas kesehatan di Puskesmas Sering bahwa ada kebijakan dari Departemen Kesehatan yang menjadi indikator dari pelaksanaan program diare 
Jurnal Kesehatan Masyarakat \& Gizi, e-ISSN: 2655-0849

Vol. 2 No.1 Edisi Mei-Oktober 2019

https://ejournal.medistra.ac.id/index.php/JKG

Received: 05 Oktober 2019 :: Accepted: 14 Oktober 2019 :: Published: 31 Oktober 2019

tetapi petugas tidak menjelaskan secara terperinci bagaimana bentuk dari kebijakan pelaksanaan program. Tenaga kesehatan yang berperan dalam pelaksanaan program diare di Puskesmas Sering juga jarang melakukan penyuluhan tentang diare. Petugas puskesmas melakukan promosi kesehatan tentang diare hanya 1 kali dalam sebulan. Penyuluhan tentang diare ke sekolah juga masih kurang dilaksanakan. Masyarakat di wilayah kerja Puskesmas Sering juga tergolong tidak aktif.

Monitoring di Puskemas Sering juga masih belum maksimal, jika dilihat dari pelaporan data tentang kasus diare, dalam 3 tahun terakhir ini puskesmas hanya menerima data kasus diare dari puskesmas pembantu (pustu) saja, kerjasama antara klinik dan puskesmas masih baru berjalan di awal tahun 2019, padahal data kasus diare juga diperlukan dari klinik di area wilayah kerja Puskesmas guna untuk memastikan bahwa penanganan kasus diare sudah dilaksanakan dengan baik sesuai dengan wilayah kerja puskesmasnya.

Pelaporan data dari klinik juga masih sering terlambat. Penyimpanan data hasil laporan juga belum baik. Sarana yang ada dalam menunjang pelaksanaan program diare juga masih minim yaitu hanya tersedia 1 leaflet saja dan tidak ada poster tentang pencegahan diare. Pemberian oralit juga belum sepenuhnya terlaksana dengan baik, hal ini disebabkan penyuluhan penggunaan oralit masih kurang disampaikan dalam penyuluhan.

Oleh karena itu berdasarkan data diatas, penulis ingin melakukan penelitian untuk menganalisis pelaksanaan program penatalaksana dia re di Puskesmas Sering Kecamatan Medan Tembung Tahun 2019.

\section{METODE PENELITIAN}

Rancangan penelitian Analisis Pelaksanaan Program Diare Di Puskemas Sering Kecamatan Medan Tembung merupakan penelitian kualitatif dengan metode deskriptif study, untuk mengeksplorasi situasi sosial yang akan diteliti secara menyeluruh, luas dan mendalam dengan melakukan wawancara mendalam, observasi dan dokumentasi.

Penelitian ini dilakukan di Puskemas Sering Kecamatan Medan Tembung yang dilaksankan pada tanggal 25 juli tahun 2019 sampai dengan selesainya penelitian pada tanggal 1 agustus 2019. Populasi dan sampel pada penelitian ini yaitu 1 Bagian PMK Dinas Kesehatan Kota Medan, 1 Kepala Puskemas Sering, 1 Penanggung jawab Program/Petugas Diare, 1 kader posyandu, 2 ibu balita yang anaknya menderita diare. Jumlah keseluruhan dari sampel pada penelitian ini berjumlah 6 orang.

Pengambilan data dalam penelitian ini dilakukan secara langsung dengan mewawancarai responden secara mendalam serta melakukan observasi di Puskemas Sering Kecamatan Medan Tembung. Data yang diambil meliputi data primer dan data sekunder.

\section{HASIL DAN PEMBAHASAN}

\section{Pengaruh Kebijakan Terhadap Pelaksanaan Program Diare di Puskesmas Sering Tahun 2019}

Berdasarkan hasil penelitian di Puskesmas Sering Kecamatan Medan Tembung Tahun 2019 bahwa kebijakan memiliki pengaruh terhadap pelaksanaan program diare. Hal yang menjadi indikator dari kebijakan mempengaruhi pelaksanaan program diare di Pusksesmas Sering adalah bahwa kebijakan terkait program diare dikhususkan pada kejadian luar biasa (KLB). Jika KLB terjadi maka hal itu wajib dipantau, kemudian melaksanakan supervisi ke tempat kejadian KLB 
tersebut. Informan juga menyatakan jika ada 10 orang menderita diare dan sudah pada tahap opname di rumah sakit maka hal tersebut dapat dinyatakan kejadian luar biasa (KLB). Setiap bulan puskesmas pembantu (PUSTU) yang ada di wilayah kerja puskesmas harus melaporkan data penderita diare, bukan hanya pustu saja tetapi klinik yang ada di wilayah kerja puskesmas juga ikut melaporkan data terkait kasus diare.

Pelaksanaan pojok oralit sebagai salah satu kebijakan dari pelaksanaan program diare juga sudah dilaksanakan oleh Puskesmas Sering. Surveilans juga termasuk dalam pelaksaan program diare, hal ini diperoleh dari pernyataan informan 3 yaitu bahwa diare juga termasuk dalam pelaporan data surveilans, dimana data tersebut dilaporkan setiap minggu ke dinas kesehatan kota medan. Diare termasuk dalam surveilans karena diare tergolong dalam penyakit yang berpontensi menyebabkan terjadinya wabah.

Kebijakan program diare di Puskesmas Sering sudah cukup baik dalam pelaksanaannya hanya saja belum mencapai kategori maksimal. Kebijakan yang disampaikan oleh 3 informan hanya berfokus ketika kasus diare sampai pada kejadian luar biasa (KLB), dan pelaporan kasus saja. Padahal penting sekali terlaksananya sistem kewaspadaan dini (SKD), pengembangan pedoman penyakit diare, peningkatan pengetahuan dan keterampilan petugas dalam pengolahan program, mengembangkan jejaring program dan lintar sektor, serta pelaksanaan monitoring evaluasi dalam pelaksanaan program diare agar bisa berjalan dengan optimal. Apabila hal-hal tersebut dapat dilaksanakan dengan baik, maka kasus diare dapat diminimalisir.

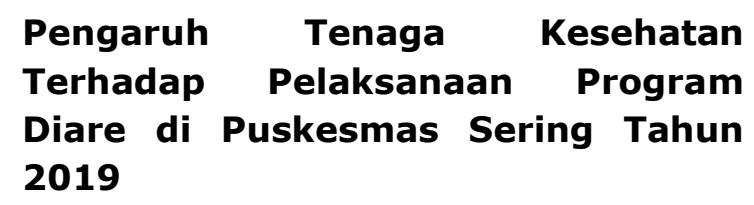

Berdasarkan hasil penelitian di Puskesmas Sering Kecamatan Medan Tembung Tahun 2019 bahwa tenaga pelaksana memiliki pengaruh terhadap pelaksanaan program diare. Hal yang menjadi indikator dalam mempengaruhi tenaga pelaksana terhadap pelaksanaan program diare di Pusksesmas Sering adalah berdasarkan jawaban dari informan 2, 3 dan 4 menyatakan bahwa tenaga kesehatan yang ikut berperan antara lain penanggungjawab program diare, UKS sekolah, dokter, petugas kesehatan lingkungan, petugas UKS yang ada di puskesmas, kader posyandu, bidan serta klinik yang ada di wilayah kerja Puskesmas Sering. Petugas kesehatan lingkungan (KESLING) berperan dalam membantu melaksanakan pencegahan diare dengan cara menjaga lingkungan tetap bersih, dilaksakannya kegiatan gotong royong yang dilakukan 2 kali dalam seminggu setiap hari sabtu. Bidan juga ikut berperan dalam pelaksanaan program diare yaitu melaksanakannya penyuluhan kepada ibu balita ketika posyandu sedang berlangsung, dengan diberikannya informasi kesehatan terkhusus tentang diare, kemungkinan besar ibu balita dapat mencegah terjadinya diare pada anaknya atau bisa melaksanakan pertolongan pertama dengan larutan gula garam (LGG) kepada anaknya yang sedang menderita diare. Tenaga kesehatan yang sudah pernah mendapatkan pelatihan hanya penanggungjawaab program saja, kader sebagai orang yang paling dekat dengan masyarakat dari perwakilan puskesmas juga seharusnya mendapatkan pelatihan, terutama pelatihan manajemen terpadu balita sakit berbasis masyarakat (MTBS).

\section{Pengaruh Sarana Prasarana Terhadap Pelaksanaan Program Diare di Puskesmas Sering Tahun 2019}

Berdasarkan hasil penelitian di

Puskesmas Sering Kecamatan Medan Tembung Tahun 2019 bahwa sarana 
prasarana memiliki pengaruh terhadap pelaksanaan program diare. Hal yang menjadi indikator sarana prasarana memiliki pengaruh terhadap pelaksaaan program diare adalah dilihat dari telah dilaksanakannya pojok oralit untuk penderita diare yang yang disertai indikasi. Berdasarkan pernyataan dari penanggungjawab program sebagai informan 2 menjelaskan bahwa keberadaan pojok oralit tidak harus selalu di sudut atau pojok ruangan, tetapi adanya ruang khusus untuk melaksanakan tatalaksana pengobatan diare. Kerjasama antara lintas program juga dibutuhkan contohnya kerjasama dengan lintas program kesehatan lingkungan (KESLING) dalam membuat penyuluhan. Kemudian dalam hal pelaporan data, penanggungjawab program sudah mengunakan komputer dan melaporkan data dalam bentuk excel. Kerjasama antara puskesmas dan klinik juga baru dilaksanakan pada tahun 2019, sebelumnya data kasus diare hanya diperoleh dari pustu saja.

Media dalam penyampaian informasi kesehatan juga dibutuhkan. Informan 2 menyatkan bahwa Puskesmas Sering hanya memilki 1 buah leaflet saja. Ketersediaan lembar balik sebagai media penyampaian informasi juga belum semua pueskesmas mendapatkannya.

Hasil penelitian Dwi (2013) menyatakan bahwa ketersediaan sarana dan prasarana usaha kesehatan sekolah memiliki hubungan yang signifikan dengan peningkatan perilaku hidup sehat. Seharusnya sarana dan prasarana di puskesmas harus lengkap agar pelaksanaan dari sebuah program dapat berjalan dengan baik. Sesuai dengan yang telah ditetapkan oleh Kemenkes RI tahun 2011 bahwa leaflet harus selalu tersedia, lembar balik juga seharusnya sudah diberikan kepada setiap puskesmas sebagai media penyampaian informasi ketika petugas kesehatan mengedukasi di ruang pojok oralit.

\section{Pengaruh Promosi Kesehatan Terhadap Pelaksanaan Program Diare di Puskesmas Sering Tahun 2019}

Hasil penelitian di Puskesmas Sering Kecamatan Medan Tembung Tahun 2019 menyatakan bahwa promosi kesehatan memiliki pengaruh terhadap pelaksanaan program diare. Hal ini dilihat berdasarkan pernyataan informan 2 dan 4 menyatakan bahwa kegiatan promosi kesehatan atau penyuluhan diare ada dilakukan di Puskesmas Sering hanya saja masih jarang, penyampaian informasi tentang diare dilakukan jika topik utama berhubungan dengan penyakit diare dan itupun dijelaskan secara garis besar saja. Informan 3 menyatakan bahwa promosi kesehatan juga disampaikan dari pihak kesehatan lingkungan dangan membuat penyuluhan cara mencuci tangan dengan sabun, melaksanakan pengawasan depot air minum yang ada di wilayah kerja Puskesmas Sering, melaksanakan pemeriksaan mikrobiologi secara berkala. $\mathrm{Hal}$ ini dilakukan untuk mencegah terjadinya diare di wilayah kerja puskesmas. Sementara pernyataan dari 2 ibu balita yang anaknya menderita diare menyatakan bahwa ibu balita tidak begitu mengingat hal apa saja yang diabahas dalam penyuluhan tentang diaretersebut, dan ibu balita yang satu menyatakan bahwa belum pernah mengikuti penyuluhan.

\section{Pengaruh Monitoring Evaluasi Terhadap Pelaksanaan Program Diare di Puskesmas Sering Tahun 2019}

Berdasarkan hasil penelitian di Puskesmas Sering Kecamatan Medan Tembung Tahun 2019 bahwa monitoring evaluasi memiliki pengaruh terhadap pelaksanaan program diare. Diketahui pernyataan dari 3 informan menyatakan bahwa monitoring dan evaluasi sudah dilaksanan oleh pihak dinas kesehatan, dengan cara membuat rapat bulanan 
Jurnal Kesehatan Masyarakat \& Gizi, e-ISSN: 2655-0849

Vol. 2 No.1 Edisi Mei-Oktober 2019

https://ejournal.medistra.ac.id/index.php/JKG

Received: 05 Oktober 2019 :: Accepted: 14 Oktober 2019 :: Published: 31 Oktober 2019

dengan seluruh penanggung jawab programdari setiap puskesmasdi dinas kesehatan kota medan. Kemudian melakukan supervisi ke lapangan, observasi kelapangan dilakukan untuk melihat apakah hal-hal yang selama ini yang telah disampaikan sudah dilaksanakan atau belum. Kemudian membuat POA untuk mengatasi hal - hal yang akan mungkin terjadi di dalam satu tahun mendatang, yang juga akan membahas apa saja hambatan dalam pelaksanaan program, serta bagaimana mengatasinya. Dan untuk membuat halhal apa saja yang aka dilakukan dimasa yang akan datang.

Hanya saja pelaksanaan dari MONEV belum optimal sehingga pelaksanaan program di lapangan juga belum berjalan sesuai dengan yang dirapkan. Dari hasil wawancara yang dilakukan dengan penanggungjawab program diare di Puskesmas Sering, bahwa sebulan sekali dilakukan rapat antara penanggung jawab program dengan bagian PKM Dinas Kesehatan di kantor Dinas Kesehatan, dan pelaksanaan turun kelapangan hanya dilakukan 1 kali dalam setahun tepatnya dibulan desember. Hal ini yang mempengaruhi kenapa program diare tidak berjalan dengan yang seharusnya, karena kurangnya monitoring dan evaluasi terhadap pelaksanaan program tersebut. Sementara hasil wawancara dengan pihak PMK Dinas Keshatan Kota Medan menyatakan bahwa untuk tahun 2019, MONEV baru akan dilakukan 3-4 kali dalam setahun. PMK sendiri menyatakan hal ini dilakukan agar tenaga kesehatan yang ada di puskesmas tidak lalai dalam menjalankan tugasnya sesuai dengan standar yang ada.

\section{KESIMPULAN}

1. Ada pengaruh Kebijakan terhadap Pelaksanaan Program Diare di Puskesmas Sering Tahun 2019

2. Ada pengaruh Tenaga Kesehatan terhadap Pelaksanaan Program
Diare di Puskesmas Sering Tahun 2019

3. Ada pengaruh Sarana Prasarana terhadap Pelaksanaan Program Diare di Puskesmas Sering Tahun 2019

4. Ada pengaruh Promosi Kesehatan terhadap Pelaksanaan Program Diare di Puskesmas Sering Tahun 2019

5. Ada pengaruh Monitoring dan Evaluasi terhadap Pelaksanaan Program Diare di Puskesmas Sering Tahun 2019

\section{SARAN}

1. Kepada Dinas Kesehatan Kota Medan agar dapat melakukan pelatihan terhadap tenaga kesehatan khususnya petugas yang sering menangasi kasus diare agar dapat meningkat pengetahuan tentang diare dan diharapkan adanya instruksi yang jelas dan tegas serta pengawasan, pembinaan dan evaluasi yang jelas dari Dinas Kesehatan Kota Medan terkait program diare.

2. Kepada Puskesmas Sering agar penyuluhan diare direncanakan dengan baik secara rutin dan berkesinambungan.. Hal ini bertujuan untuk meningkatkan pengetahuan dan keterampilan masyarakat khususnya ibu balita, sehingga ibu balita dapat mencegah penyakit diare dan melakukan pertolongan pertama saat anaknya mengalami diare.

3. Diharapkan kepada masyarakat di wilayah kerja Puskesmas Sering agar dapat menjaga kebersihan lingkungan dan dapat melaksanakan perilaku hidup bersih dan sehat (PHBS) dan mau ikut serta dalam kegiatan penyuluhan yang dilaksanakan oleh pihak puskesmas.

\section{DAFTAR PUSTAKA}


Jurnal Kesehatan Masyarakat \& Gizi, e-ISSN: 2655-0849

Vol. 2 No.1 Edisi Mei-Oktober 2019

https://ejournal.medistra.ac.id/index.php/JKG

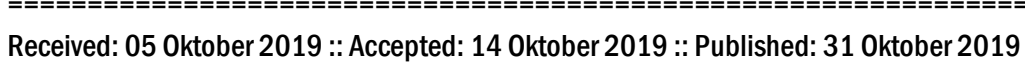

Dermawan, E.S., \& Sjaaf, A.C. (2016). Administrasi Kesehatan Masyarakat : Teori dan Praktik. Jakarta : PT Rajagrafindo Persada

Firdaus, J.K. (2013). Pengantar Epidemiologi Penyakit Menular : Untuk Mahasiswa Kesehatan Masyarakat. Jakarta : TIM

Kementerian Kesehatan RI. (2011)

Situasi Diare Di Indonesia. ISSN 2088 - 207X. 2011-07.

Kementerian Kesehatan RI. 2015. Keputusan Menteri Kesehatan Republik Indonesia Nomor HK.02.02/Menkes/52/2015.

Tentang Rencana Startegis Kementerian Kesehatan Tahun 2015 - 2019. - Jakarta : Kementerian Kesehatan RI

Mubarak, W.I., \& Chayatin, N. (2009). IImu Kesehatan Masyarakat : Teori dan Aplikasi. Jakarta : Salemba Medika

Puskesmas Rampal Celaket. (2017). Rencana Usulan Kegiatan Program Diare. Malang

Sugiyono. (2011). Metode Penelitian Kuantitatif, Kualitatif, dan R\&D. Bandung : Alfabeta

Suharyono. (2012). Diare Akut Klinik dan Laboratorik. Jakarta : Rineka Cipta

Sumantri, Arif. (2011). Metodologi Penelitian Kesehatan. Jakarta : Kencana Prenada Media Group

Surachman, Rendita Herditiya. (2011) Pengaruh Faktor Lingkungan dan Karakteristik Ibu terhadap Tindakan Penanganan Diare pada Balita di Kelurahan Kota Bangun Kecamatan Medan Deli Kota Medan Tahun 2009. Skripsi, Universitas Sumatera Utara.

Susi.H\& Nurazila. (2018). Faktor Yang Mempengaruhi Kejadian Diare Pada Balita di Wilayah Kerja
Puskesmas Rejosari

Pekanbaru. Jurnal Endurance, 3 (2) Juni 2018 (400-407), pp. 400-401

Syarifudin, Theresia \& Jomima. (2009). Buku Ajar Ilmu Kesehatan Masyarakat Untuk Mahasiswa Kebidanan. Jakarta : TIM

Undang - Undang Republik Indonesia Nomor 36 Tahun 2009. Tentang Kesehatan

Widoyono. (2008). Penyakit Tropis Epidemiologi, Penularan \& Pemberantasannya. Jakarta : Erlangga 